\title{
A financeirização do noticiário econômico: 0 uso de estratégias de comunicação por grupos de interesse e seu impacto nos conteúdos jornalísticos
}

\section{Paula Puliti}

\section{Resumo}

A imprensa é uma instituição legitimada socialmente pela defesa da pluralidade de visões que marca os ambientes democráticos. É a partir do conhecimento de diferentes aspectos da realidade e de opiniões, que o indivíduo constrói a visão de mundo que lhe permitirá exercer seus direitos de cidadão. Numa era em que as informações estão dispersas, o jornalista tem 0 papel de ordená-las e oferecê-las ao leitor, definindo as agendas locais, nacionais e mundiais. Por conta de sua legitimidade social e capacidade de definir as agendas, a imprensa é alvo prioritário de diversos grupos de interesses - como políticos, empresários, banqueiros, ONGs e sindicatos -, que pretendem ver suas ideias espelhadas em uma instituição de alto respeito. 0 objetivo deste trabalho é discutir a ação de grupos de interesse no noticiário econômico, a partir de um recorte cujo sujeito é o mercado financeiro e sua predominante presença em jornais de conteúdo geral, conforme mostram os resultados de pesquisa realizada com $O$ Estado de S. Paulo e Folha de S.Paulo no período 1989-2002

\section{Palavras-chave:}

Jornalismo brasileiro. Jornalismo econômico.

Noticiário econômico. Jornalismo e mercado financeiro.

Financeirização do noticiário.

Paula Puliti I paula.puliti@usp.br

Doutora em Comunicação Social pela Escola de Comunicações e Artes da Universidade de São Paulo (ECA-USP);

Mestre em International History pela London School of Economics and Political Science (LSE) da University of London, com bolsa do British Council; Jornalista.

\section{Introdução}

Entre os leitores de jornal, é comum a

percepção de que há certa monocordia temática no noticiário econômico. 0 nível de gastos públicos, o endividamento do governo e as variáveis econômicas que podem influenciar 0 comportamento dos juros básicos da economia a Taxa Selic, definida pelo Banco Central - são os assuntos que parecem predominar nas páginas de economia dos jornais. Os preços dos alimentos, dos produtos e das tarifas públicas, temas tão importantes ao brasileiro, praticamente só são abordados quando adequados a matérias de política monetária - se 0 governo vai ter de elevar os juros para cumprir metas de inflação e superávit de contas públicas.

0 que a análise do noticiário econômico nos revela, de forma mais concreta, é a predominância de abordagens e temas que refletem quase que exclusivamente uma linha de pensamento: o neoliberalismo financeiro, sua visão sobre a política de juros e 0 endividamento federal. Entre as fontes privadas, os profissionais do sistema bancário e da rede de consultores 
que gira em torno das altas finanças prevalecem até mesmo sobre os empresários, antes predominantes, caracterizando uma linha editorial batizada de financeirização do noticiário. 0 termo financeirização é uma espécie de neologismo. Foi concebido como o predomínio no noticiário de assuntos que resultam da convergência entre os interesses de lucro do sistema financeiro e a ideologia neoliberal.

Enquanto doutrina, pode-se dizer que 0 neoliberalismo é um corpo de regras que defende 0 livre mercado acima de quaisquer outros interesses. E para que 0 interesse privado esteja no controle da vida pública, é necessário que o Estado esteja ausente. É por isso que os neoliberais defendem incondicionalmente as privatizações e 0 enxugamento fiscal (RAMONET, 1995) 0 neoliberalismo prega, como ideologia, que não há nada mais ineficiente do que o Estado e nada mais moderno e eficiente do que as forças do "mercado" - o local hipotético onde cada indivíduo seria capaz de tomar decisões próprias. Em tese, quanto menores 0 aparato estatal e os gastos públicos, melhor caminha a vida dos indivíduos e a economia de um país. Quanto mais liberdade de autorregulação, melhor o setor privado atenderia às demandas sociais.

Falar sobre financeirização no atual momento histórico-econômico coincide com as graves crises que grandes economias mundiais atravessam, provocadas justamente pela ausência de regras que rejam o mundo das altas finanças. Depois da simbólica quebra do banco norteamericano Lehman Brothers, em 2008, governos dos Estados Unidos e de países europeus buscam, agora, impor regras mais rígidas aos arriscados negócios do mercado financeiro, mas ainda não obtiveram sucesso. Nas sociedades em que os pilares culturais são o livre mercado e a livre iniciativa, há enorme resistência à imposição de regras pelo Estado.

A financeirização não é um momento novo do noticiário econômico. Na verdade, teve início no Brasil a partir da redemocratização do final dos anos 1980, ganhou corpo no primeiro mandato do governo Fernando Henrique Cardoso e consolidou-se no segundo período da chamada era FHC, iniciada em 1995 e encerrada no primeiro dia de 2003. Considerando-se que a financeirização ainda prevalece é preciso discutir por que a imprensa praticamente ignora vozes dissonantes das do neoliberalismofinanceiro, permitindo que uma única visão de mundo influencie o pensamento social e as agendas nacionais.

Em termos estritamente da relação jornal/ leitor, em que os periódicos precisam de leitores para sobreviver, o noticiário econômico financeirizado pouco interesse desperta entre os não-especializados ${ }^{2}$. Uma pesquisa realizada pela 
agência Ipsos-Marplan em meados dos anos 1990 revela, por exemplo, que apenas $25 \%$ dos leitores de Folha de S.Paulo, O Estado de S. Paulo e O Globo leem o noticiário econômico. 0s 75\% que deixam de lado as páginas de economia o fazem porque não entendem o que está escrito ali, não veem relação do noticiário com seus cotidianos. A mesma pesquisa revelou que as notícias econômicas ocupam a $12^{\mathrm{a}}$ posição na lista dos temas preferenciais - de um total de 18 - entre os assinantes daqueles mesmos diários. É claro que cada leitor tem suas preferências temáticas e isso não está em discussão. 0 que se discute é por que a economia em seu aspecto social - tão presente na vida de todos e tão fundamental para a tomada de decisões - é ignorada por três em cada quatro leitores de jornal. Algo não se encaixa.

Este artigo procura discutir as implicações que 0 predomínio de um grupo de interesse no noticiário pode ter sobre o caráter de pluralidade que a imprensa desfruta em ambientes democráticos.

\section{A financeirização se revela}

0 conteúdo do noticiário econômico praticado nos jornais gerais brasileiros iniciou um processo de transformação a partir da segunda metade dos anos 1980, dentro de um trajeto de redemocratização política e de adoção de novas políticas econômicas - endossadas pelo
Fundo Monetário Internacional (FMI) e o Banco Mundial (Bird) -, segundo as quais as forças que levam ao desenvolvimento só se realizam quando, liberadas das amarras do Estado, se encontram e tomam suas decisões em um ambiente de mercado livre. Essa transformação, que praticamente alijou do noticiário outras linhas de pensamento, foi batizada de financeirização e revela a bem-sucedida estratégia comunicacional de um grupo disposto a influir na agenda nacional.

Mas antes de se discutir as implicações da financeirização, é necessário comprovar sua existência. Levantamento realizado para identificar no noticiário econômico o nível de penetração de temas de interesse do círculo financeiro analisou 580 matérias de alto de página dos jornais o Estado de S.Paulo e Folha de S.Paulo, retiradas de uma amostra de 14 semestres entre 1989 e 2002, período que inclui a fase final do primeiro governo civil pós-Golpe de 64 com o presidente José Sarney (1985-1990), passando pelos governos de Fernando Collor de Mello (1990-1992), Itamar Franco (1992-1995) e Fernando Henrique Cardoso (1995-2003).

A partir de uma lista de temas associados ao neoliberalismo-financeiro, o resultado revelou que os assuntos relacionados à financeirização apareceram na liderança da lista dos cinco de maior prevalência em 13 anos. A exceção 
foi 1989, quando predominaram questões trabalhistas (greves, demissões e negociação salarial). De 1990 a 1994, as notícias sobre 0 comportamento do mercado financeiro dividiram espaço de forma praticamente equilibrada com greves, negociações salariais e inflação. Depois desse período, predominaram exclusivamente o comportamento do mercado financeiro e as notícias sobre reformas, privatizações, contas públicas, abertura da economia e desregulamentação do setor privado.

Em outro levantamento, com uma amostra ampliada para 2.340 itens de todo o noticiário econômico e não apenas os abres-de-página, verificou-se quais são as categorias de fontes que prevaleceram nas páginas de economia dos jornais. 0 resultado revelou que as fontes do setor financeiro predominaram em 11 dos 14 semestres analisados, sendo que em 1992 observou-se uma importante mudança no noticiário. A partir daquele ano, os profissionais do mercado financeiro deixaram de aparecer exclusivamente em matérias sobre investimentos e passaram a repercutir ações do governo, sobretudo as ligadas às reformas recomendadas pelo "Consenso de Washington" (receituário econômico neoliberal para países em desenvolvimento, que previa reformas, privatizações e rigidez fiscal). Os financistas não apenas eram ouvidos para comentar os movimentos do mercado de capitais, mas também estenderam sua influência sobre o noticiário macroeconômico. Um dado de 1998 chegou inclusive a surpreender: profissionais do mercado financeiro apareceram como fonte em 25\% das notícias sobre demissões na indústria, revelando a penetração do pensamento financista até em temas fora de sua alçada33.

Os resultados mostram que foram perdendo espaço no noticiário questões que tinham um pouco mais a ver com o dia a dia dos leitores não-especializados, como relações trabalhistas, mercado de trabalho, atividade agropecuária e produção industrial - dois setores altamente empregadores no estado de São Paulo - além, e principalmente, de matérias sobre direito do consumidor. Esses temas, se não abordados dentro da ótica monetarista regida pelo binômio inflação/juros, perderam qualquer importância. É importante ressaltar que, ao mesmo tempo, o discurso econômico refletido nos jornais passou por importantes mudanças. Tornou-se tão complexo que só iniciados conseguem entender. Não chega ao leitor comum. Com a adoção do modelo neoliberal a partir de Fernando Collor de Mello, o que se viu foi a emergência de matérias sobre reformas - da Previdência, do sistema tributário e das leis trabalhistas - abertura comercial e de serviços, e, principalmente, orçamento e contas públicas, exacerbando-se 0 uso do economês, aquela linguagem que só os "iniciados" entendem: captações, spreads, balanço 
de pagamentos, títulos do Tesouro, ações, câmbio, swaps, mercado financeiro, déficit fiscal, superávit primário, valor de mercado, risco-país, leilões de dólares, indicadores antecedentes, curva de juros, rentabilidade e outros termos técnicos.

\section{A financeirização e as estratégias comunicacionais}

Foi a partir da adoção do Plano Real, em 1994, que as ideias do sistema financeiro se consolidaram no noticiário. Com o governo Fernando Henrique Cardoso buscando as reformas modernizadoras para levar o Brasil a se beneficiar do enorme fluxo de dinheiro que buscava rendimentos altos pela via do mercado financeiro, muitos bancos adotaram - e outros apenas reforçaram - uma série de estratégias comunicacionais para construir espaços na imprensa, aparecendo como a fonte mais qualificada para falar de temas econômicos.

Entrevistas dirigidas com uma amostra de 34 analistas econômicos de diferentes bancos participantes da pesquisa Focus do Banco Central revelaram a adoção de estratégias - que se provaram acertadas - dentro de um movimento próprio do sistema financeiro de tentar influir na agenda nacional a partir do apoio da imprensa a suas ideias. Envolto na aura de cientificidade a ele conferida pela vertente do cálculo contida nas Ciências Econômicas, o profissional do sistema financeiro (não o banqueiro, esse nunca quis aparecer, mas seus funcionários) construiu uma importante relação com o jornalista.
Dotado de um discurso racional, moderno e apolítico, passou a ser valorizado como portavoz das instituições. Recebeu treinamento para falar com os jornalistas e começou a distribuir diariamente seus trabalhos de análise, concebidos para clientes pagantes, também às redações. Esse relatório diário do economista em parte substituiu o press release convencional, pois se apresenta praticamente como um documento científico.

Todas as 34 instituições ouvidas têm departamentos econômicos e a função dessas áreas é preparar material de análise e opinião para ser vendido a clientes corporativos. Só que $82 \%$ desses mesmos departamentos enviam esse material para os jornalistas. Se há envio de material às redações, há intenção de contato. Cada um desses relatórios vem com nome, e-mail e telefone do profissional que o elaborou. É comum ainda que os próprios economistas façam as vezes do assessor de imprensa, enviando eles mesmos material com suas opiniões, trocando e-mails e oferecendo aos jornalistas os telefones de suas mesas e os celulares.

\section{A problemática da financeirização para o jornalismo}

Partimos do princípio de que o jornalismo é um campo legitimado pela ideia de que a democracia é um regime político superior. Dentro dessa ideologia, caberia à imprensa vigiar o poder político e proteger os cidadãos dos eventuais abusos dos governantes, além de 


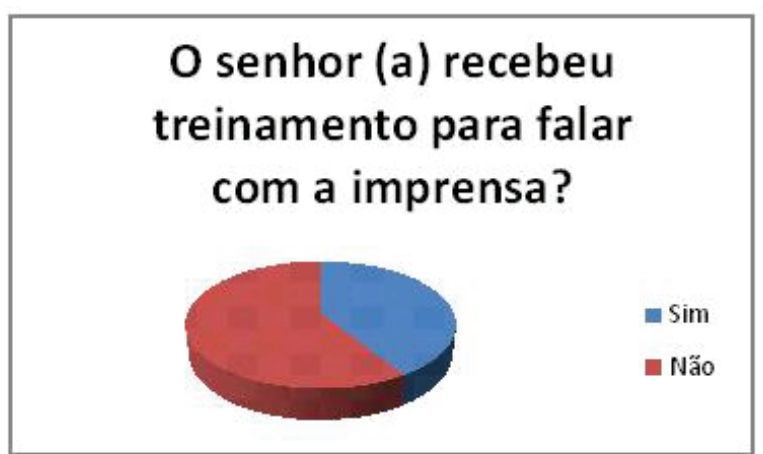

Fonte: A Finalização do Noticiário Ecônomico (1989-2002). Tese definida em novembro de 2009

Quadro 2: pesquisa c/ agentes do mercado financeiro

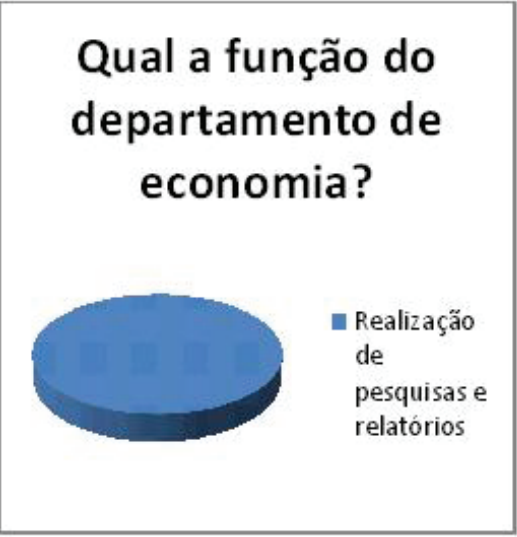

Quadro 3 pesquisa c/ agentes do mercado financeiro

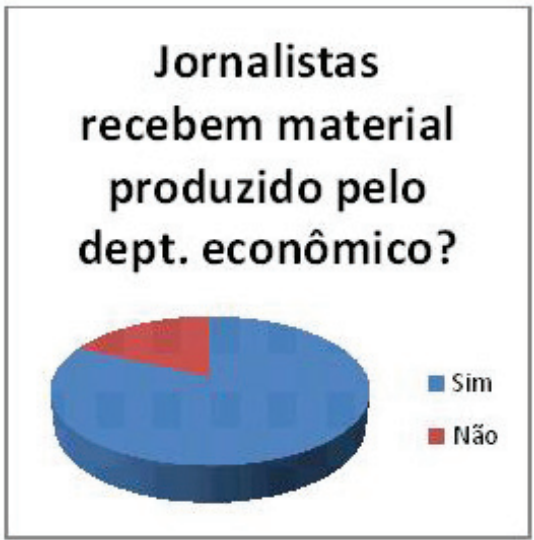

Fonte: A Financeirização do Noticiário Econômico (1989-2002) (PULITI, 2009).

fornecer aos cidadãos informações necessárias para o desempenho de suas responsabilidades cívicas (TRAQUINA, 2004). 0 ethos contemporâneo da profissão, que se formou a partir das estreitas ligações do jornalismo com os ambientes democráticos, é o de trabalhar com a verdade, de forma neutra, imparcial e objetiva. É isso que lhe garante credibilidade perante a sociedade. Os jornalistas são vistos como os responsáveis pela transparência da administração pública e pela denúncia e vigilância do poder político, através da incumbência, que lhe atribuem os espectadores, de fornecer-lhes a essência dos fatos políticos (ALDÉ, 2004).

Em uma era de dispersão das informações e comunicação de massa, os jornalistas têm ainda o papel de organizar conteúdos para apresentá-los à sociedade, refletindo códigos de ética aplicada que, embora variem de sociedade para sociedade, enfatizam a busca da verdade e do interesse público. Eles é que teriam o poder de reconhecer a notícia e de projetá-la para além de sua própria circunscrição, bem como legitimar 
os entrevistados perante a sociedade como detentores de algum conhecimento específico.

Pensando em termos teóricos, os profissionais da notícia funcionariam como gatekeepers (porteiros) das informações, deixando passar algumas e barrando outras. 0 que o público sabe e com o que se importa em dado momento é, em grande parte, um produto do gatekeeping midiático, segundo a teoria de agenda-setting. Na prática, os jornalistas definem o que vai virar notícia diante de critérios de noticiabilidade ${ }^{4} \mathrm{e}$ de interações entre os próprios jornalistas (que reivindicam o monopólio de saber o que é notícia) e os diversos agentes sociais, que pretendem usar as notícias como um recurso de comunicação com a sociedade. E justamente por ser um opinion maker o jornalista é disputado por grupos de interesse (ALDÉ; XAVIER; CHAGAS, 2005). Mas tornar-se fonte dos jornalistas não é um processo natural. Ao contrário, na maioria das vezes é um caminho estrategicamente construído. É a profissionalização da relação com os jornalistas que garante espaço aos diversos agentes e, nesses termos, pode-se dizer que o acesso ao campo jornalístico é uma conquista (ALDÉ, 2004)5 .

Além disso, os discursos que a imprensa transmite definem as agendas das cidades, dos países e do mundo. Os discursos - por mais neutros que pareçam - são poderes em operação, constroem visões de mundo e encerram projetos de controle (GOMES, 2003, p. 45) ${ }^{6}$. Pensemos exclusivamente no setor privado. Para influenciar a contento políticos e os diversos níveis do governo passando para a sociedade a visão de que suas ideias são de interesse de todos -, o grupo de interesse precisa construir, primeiramente, uma rede de apoio além dela própria que lhe dê credibilidade. Essa rede é formada basicamente pela academia e pela imprensa.

Mas é preciso dizer que se trata de uma relação simbiótica. Os grupos de interesse querem a cooperação dos jornalistas para aparecer, e os jornalistas querem a cooperação dos grupos para

A noticiabilidade, segundo Wolf (2001), é a aptidão de um fato para tornar-se notícia. Podem-se destacar entre esses critérios (ou valores-notícia):

Momento do acontecimento: quanto mais as características temporais servirem às necessidades do meio, mais facilmente um fato vira notícia;

Intensidade: quanto maior a magnitude de um acontecimento, maior a probabilidade de ser noticiado;

Clareza: a inexistência de dúvidas é diretamente proporcional à hipótese de um evento se tornar notícia;

Surpresa: quanto mais inesperado o fato ou o dado, maiores chances de virar notícia;

Continuidade: a noticiabilidade de um acontecimento aumenta as chances de haver repercussões a partir dele, gerando mais notícias para os dias seguintes;

Valores socioculturais: 0 valor-notícia varia de acordo com padrões culturais vigentes.

Antes mesmo da existência da comunicação de massa, Marx e Engels (2002) desenvolveram a noção de que qualquer grupo que aspira ter suas ideias predominantes na sociedade deve apresentá-las como sendo de interesse de todos.

Não estamos nos referindo à discussão, muito frequente aliás, de que os meios de comunicação transmitem as ideias de seus proprietários. A questão aqui é o poder da fonte sobre o noticiário 
ter notícias. É essa cooperação que vai responder, em grande medida, à escolha de determinado tema e enfoque no noticiário em detrimento de outros assuntos e agentes (STEINER, 2006). Enquanto os jornalistas precisam ter diariamente ideias de matérias e fontes disponíveis, as fontes precisam dos meios para se comunicar com os ambientes externos, numa relação de recíproca conveniência (CHAPARR0, 1994, p. 73). Analisando a relação entre mercado financeiro e jornalismo, Grün (2005) é enfático. Para ele, os financistas sabem muito bem o grau de impacto que as notícias têm sobre o próprio mercado e a agenda nacional. Por isso, têm como hábito cortejar os jornalistas.

Tendo em mente a ideia de cooperação, o sistema financeiro investiu em comunicação. Antes da redemocratização do país, profissionais do sistema financeiro nem atendiam aos jornalistas. Mas com a abertura política e a mudança no regime econômico, influir na agenda nacional passou a ser uma necessidade, já que governo e seus técnicos definem as políticas de interesse do setor privado.

\section{Redações enxutas e relógios correndo cada} vez mais rapidamente contra o fechamento dos jornais levam os jornalistas a depender de um número pequeno de fontes regulares. São fontes sempre disponíveis, aptas a oferecer assuntos que podem virar matérias e que explicam as peculiaridades da macroeconomia nas pautas que envolvem engrenagens de política econômica.
Essas fontes acabam por dominar a relação.

Fontes disponíveis e de credibilidade (lembremos que os profissionais do mercado financeiro são, por assim dizer, cientistas econômicos com enorme disponibilidade para falar com os jornalistas) podem ser chamadas de definidores primários primary definers (HALL, 1973 apud TRAQUINA, 2004, p. 177-178). Eles geram os dados e fatos que irão suprir as necessidades dos jornalistas e sabem oferecer material para notícias de acordo com 0 perfil de cada veículo de comunicação.

Há claramente um conflito entre os parâmetros éticos que deveriam guiar a imparcialidade jornalística e a posição de subordinação dos jornalistas em relação aos primary definers. Na maioria dos casos, os jornalistas aceitam a definição do noticiário por parte desse grupo estrategicamente preparado. Assessorados por profissionais da comunicação, os definidores primários sabem que a rotina jornalística, sistematicamente pressionada pelo relógio, exige fatos novos todos os dias. Na prática, os economistas do mercado financeiro abastecem diariamente os jornalistas com estudos de cunho técnico, cheios de números, gráficos e projeções, sempre seguidos de comentários e interpretações. Ancorados no discurso científico, os financistas constroem sua credibilidade junto à imprensa, tornam-se fontes e se legitimam perante a sociedade como detentores do único conhecimento correto, pois quem é cientificamente reconhecido aparece como importante para os outros (DUPAS, 2005; ORTIZ, 2006). 


\section{Considerações Finais}

0 cruzamento dos resultados das pesquisas de conteúdo noticioso com o levantamento feito junto a profissionais do mercado financeiro mostra que grupos mais organizados em termos comunicacionais e com discurso técnico-racional têm, na atual realidade da produção jornalística, mais chances de entrar no noticiário. A disponibilidade da fonte e a oferta de material também são parte importante desse conjunto de estratégias, e cada vez mais 0 jornalista busca quem mais rapidamente atenda a seu telefonema. Melhor ainda, se a fonte disponível for dotada de um discurso científico. Portanto, grupos que desejam construir ou reconstruir seus espaços na imprensa precisam adotar estratégias de comunicação cada vez mais racionais e colaborativas. Cada vez menos 0 profissional de imprensa se deixa seduzir por discursos politizados.

No caso específico dos agentes do mercado financeiro, as estratégias básicas apuradas são a contratação de assessorias de imprensa e a oferta de media training àqueles que desejam ser agentes ativos na construção da agenda nacional. Mas a ação, digamos, mais subliminar dessa estratégia e a que ao mesmo tempo denota mais intenção comunicacional é 0 expressivo envio para jornalistas dos relatórios produzidos pelos departamentos de economia. Elaborados na linguagem das Ciências Econômicas, os relatórios passam um conteúdo aparentemente neutro, livre de interferências políticas e dentro de parâmetros técnicos. Mas como já foi dito, não há discurso neutro.

Há, ainda, outro aspecto que precisa ser considerado quando se analisa a valorização que os grupos privados conferem à organização comunicacional: o espaço publicitário é caro. Assim, toda vez que um profissional é citado na grande imprensa, leva junto o nome da instituição que representa, fazendo publicidade indireta.

Mas, afinal, o que tudo isso tem a ver com a ética jornalística? Nas sociedades atuais, os assuntos de economia são fundamentais para 0 exercício da cidadania. A mais abrangente fonte de informação disponível nas sociedades de massa é a imprensa - aqui a mídia televisiva tem papel fundamental? ${ }^{7}$ Por isso, os conteúdos deveriam privilegiar preceitos que garantissem 0 acesso dos cidadãos a notícias e dados que lhe digam respeito. Mas, ao favorecer ideias de um único grupo, a imprensa limita 0 debate. Ainda que não se entre no mérito de interesses escusos de cada grupo, dar espaço a uma voz como se fosse a única detentora do saber, porque seu discurso é técnico-científico e sua relação com os jornalistas é organizada, desvia-se do ethos de pluralidade e neutralidade que sempre garantiu credibilidade e legitimidade aos jornalistas. 
Portanto, o grande desafio de uma imprensa que tenha padrões éticos e democráticos é construir uma sociedade saudável e plural, o que só se consegue com equilibrio de interesses. Falta ao profissional da imprensa desafiar pensamentos pré-concebidos que se apresentam como os únicos racionais.

Significa enxergar além do discurso e questioná-lo. 0 problema ético está posto e precisa ser debatido para que se possa avaliar o real papel dos meios de comunicação em sociedades plurais e democráticas.

Muitos jovens profissionais saem da faculdade com pouca noção a respeito de como se concebe o noticiário econômico no dia a dia das redações; muitos sequer leem ou entendem o que está escrito nas páginas de economia dos jornais. Por isso, quando começam a trabalhar, tendem a reproduzir o status quo, buscando fontes já legitimadas e acessíveis, sem imaginar interesses setoriais que podem estar permeando a conversa. É possível e desejável se buscar pensadores de outras linhas que possam contribuir para um noticiário mais rico de visões.

\section{Referências}

ALDÉ, Alessandra. A construção da política: democracia, cidadania e meios de comunicação de massa. Rio de Janeiro: FGV, 2004. ; XAVIER, Gabriela B.; CHAGAS, Viktor. Critérios jornalísticos de noticiabilidade: discurso ético e rotina produtiva. Revista Alceu, Rio de Janeiro, v. 5, n. 10, pg. 186-200, jan./jun. 2005.

\section{CHAPARRO, Manuel. C. Pragmática do jornalismo:} buscas práticas para uma teoria da ação jornalística.São Paulo: Summus, 1994..
DUPAS, Gilberto. Atores e poderes na nova ordem global: assimetrias, instabilidades e imperativos de legitimação. São Paulo: Unesp, 2005.

GOMES, Maira. R. Ética e jornalismo. São Paulo: Escrituras, 2002.

GRÜN, Roberto. Convergência das elites e inovações financeiras: a governança corporativa no Brasil.

Revista Brasileira de Ciências Sociais, São Paulo, v. 20, n.58, p. 139-161, jun. 2005.

HALL, Stuart. et al. The social production in news: mugging in the media. In: COHEN, Stanley.; YOUNG, Jock. (eds.). The manufacture of news. London: Constable, 1973.

KOVACK, Bill, ROSENSTIEL, Tom. Os Elementos do Jornalismo: 0 que os jornalistas devem saber e 0 público exigir. São Paulo: Geração Editorial, 2004. MARX, Karl, ENGELS, Friedrich. A ideologia alemã. São Paulo: Martins Fontes, 2002.

ORTIZ, Renato. Mundialização: saberes e crenças. São Paulo: Brasiliense, 2006.

PULITI, Paula. A financeirização no noticiário econômico (1989-2002). 2009. Tese (Doutorado em Comunicação Social) - Escola de Comunicações e Artes, Universidade de São Paulo, São Paulo, 2009.

RAMONET, Ignacio. 0 pensamento único e os novos senhores do mundo. Cultura Brasileira, 1995. Disponível em: < http://www.culturabrasil.org/ pensamentounico ramonet.htm/>. Acesso em: 21 Mai 2008.

STEINER, Philippe. A sociologia econômica. São Paulo: Atlas, 2006.

TRAQUINA, Nelson. Teorias do Jornalismo: por que as notícias são como são (Volume I). Florianópolis: Insular, 2004.

WOLF, Mauro. Teorias da comunicação. Lisboa: Presença, 2001. 


\section{The financialization of economic news: the utilization of communication strategies by interest groups and its impact on news content}

\section{Abstract:}

The press is an institution socially legitimated as a defender of plurality of opinions, which is proper of democratic environments. It is as from the knowledge of different aspects of reality that individuals make up their minds and carry out their citizens' rights. In a time when information is all around, journalists play the role of organizing it, delivering it to readers, defining consequently the domestic and global agendas. Due to its legitimacy and agenda-setting role, the press has been targeted by several interest groups, such as NGOs, worker's unions, politicians, businesspeople and bankers, all intending to see their ideas mirrored in such respected institution. This article discusses the wellsucceeded action of interest groups on the economic session of non-specialized papers, having as subject the financial market, whose preponderancy was unveiled in a survey conducted in the news content of daily papers O Estado de S.Paulo and Folha de S.Paulo in the 1989-2002 period.

\section{Keywords:}

Brazilian journalism. Economic journalism. News and financial market. Financialization of the news.

\section{La financiarización del noticiero económico: el uso de estrategias de comunicación por grupos de presión y su impacto en los contenidos periodísticos}

\section{Resumen:}

La prensa es una institución legitimada socialmente por la defensa de la pluralidad de perspectivas que distingue los ambientes democráticos. Es a partir del conocimiento de los diversos aspectos de la realidad y de opiniones que el individuo construye la visión de mundo que le permitirá ejercer sus derechos de ciudadano. En una época en que las informaciones están dispersas, al periodista le cabe el papel de ordenarlas y ofrecérselas al lector, definiendo las agendas locales, nacionales y mundiales. Debido a su legitimidad social y capacidad de definir el orden del día, la prensa es el blanco prioritario de distintos grupos de interés. ONG, sindicatos, políticos, empresarios y banqueros se plantean ver sus posiciones reflejadas en una institución de alto respeto. El objetivo de este trabajo es el de discutir la acción de grupos de interés en el noticiero económico, a partir de un recorte cuyo sujeto es el mercado financiero y su predominante presencia en periódicos de contenido general. Se basa en los resultados de un levantamiento de los contenidos de los periódicos brasileños O Estado de S.Paulo y

Folha de S.Paulo durante el período 1989-2002.

\section{Palabras clave:}

Periodismo brasileño. Periodismo económico.

Noticiero económico. Periodismo y mercado financiero. Financiarización del noticiero. 


\section{Expediente}

A revista E-Compós é a publicação científica em formato eletrônico da Associação Nacional dos Programas de Pós-Graduação em Comunicação (Compós). Lançada em 2004, tem como principal finalidade difundir a produção acadêmica de pesquisadores da área de Comunicação, inseridos em instituições do Brasil e do exterior.
E-COMPÓS I www.e-compos.org.br I E-ISSN 1808-2599

Revista da Associação Nacional dos Programas de Pós-Graduação em Comunicação. Brasília, v.13, n.3, set./dez. 2010.

A identificação das edições, a partir de 2008 passa a ser volume anual com três números.

\section{CONSELHO EDITORIAL}

Afonso Albuquerque

Universidade Federal Fluminense, Brasil

Alberto Carlos Augusto Klein

Universidade Estadual de Londrina, Brasi

Alex Fernando Teixeira Primo

Universidade Federal do Rio Grande do Sul, Brasil

Alfredo Vizeu

Universidade Federal de Pernambuco, Brasi

Ana Carolina Damboriarena Escosteguy

Pontifícia Universidade Católica do Rio Grande do Sul, Brasil

Ana Silvia Lopes Davi Médola

Universidade Estadual Paulista, Brasil

André Luiz Martins Lemos

Universidade Federal da Bahia, Brasil

Ângela Freire Prysthon

Universidade Federal de Pernambuco, Brasil

Antônio Fausto Neto

Universidade do Vale do Rio dos Sinos, Brasil

Antonio Carlos Hohlfeldt

Pontifícia Universidade Católica do Rio Grande do Sul, Brasil

Arlindo Ribeiro Machado

Universidade de São Paulo, Brasil

César Geraldo Guimarães

Universidade Federal de Minas Gerais, Brasil

Cristiane Freitas Gutfreind

Pontifícia Universidade Católica do Rio Grande do Sul, Brasil

Denilson Lopes

Universidade Federal do Rio de Janeiro, Brasil

Eduardo Peñuela Cañizal

Universidade Paulista, Brasil

Erick Felinto de Oliveira

Universidade do Estado do Rio de Janeiro, Brasil

Francisco Menezes Martins

Universidade Tuiuti do Paraná, Brasil

Gelson Santana

Universidade Anhembi/Morumbi, Brasil

Goiamérico Felício

Universidade Federal de Goiás, Brasil

Hector Ospina

Universidad de Manizales, Colômbia

Herom Vargas

Universidade Municipal de São Caetano do Sul, Brasil

leda Tucherman

Universidade Federal do Rio de Janeiro, Brasil

Itania Maria Mota Gomes

Universidade Federal da Bahia, Brasil

Janice Caiafa

Universidade Federal do Rio de Janeiro, Brasil

Jeder Silveira Janotti Junior

Universidade Federal da Bahia, Brasil
João Freire Filho

Universidade Federal do Rio de Janeiro, Brasil

John DH Downing

University of Texas at Austin, Estados Unidos

José Luiz Aidar Prado

Pontifícia Universidade Católica de São Paulo, Brasil

José Luiz Warren Jardim Gomes Braga

Universidade do Vale do Rio dos Sinos, Brasi

Juremir Machado da Silva

Pontifícia Universidade Católica do Rio Grande do Sul, Brasil

Lorraine Leu

University of Bristol, Grã-Bretanha

Luiz Claudio Martino

Universidade de Brasília, Brasil

Maria Immacolata Vassallo de Lopes

Universidade de São Paulo, Brasil

Maria Lucia Santaella

Pontifícia Universidade Católica de São Paulo, Brasil

Mauro Pereira Porto

Tulane University, Estados Unidos

Muniz Sodre de Araujo Cabral

Universidade Federal do Rio de Janeiro, Brasil

Nilda Aparecida Jacks

Universidade Federal do Rio Grande do Sul, Brasil

Paulo Roberto Gibaldi Vaz

Universidade Federal do Rio de Janeiro, Brasil

Renato Cordeiro Gomes

Pontifícia Universidade Católica do Rio de Janeiro, Brasil

Ronaldo George Helal

Universidade do Estado do Rio de Janeiro, Brasil

Rosana de Lima Soares

Universidade de São Paulo, Brasil

Rossana Reguillo

Instituto Tecnológico y de Estudios Superiores do Occidente, México

Rousiley Celi Moreira Maia

Universidade Federal de Minas Gerais, Brasil

Samuel Paiva

Universidade Federal de São Carlos, Brasil

Sebastião Albano

Universidade Federal do Rio Grande do Norte, Brasil

Sebastião Carlos de Morais Squirra

Universidade Metodista de São Paulo, Brasil

Simone Maria Andrade Pereira de Sá

Universidade Federal Fluminense, Brasi

Suzete Venturelli

Universidade de Brasília, Brasil

Valério Cruz Brittos

Universidade do Vale do Rio dos Sinos, Brasil

Veneza Mayora Ronsini

Universidade Federal de Santa Maria, Brasil

Vera Regina Veiga França

Universidade Federal de Minas Gerais, Brasil

COMISSÃO EDITORIAL

Felipe da Costa Trotta I Universidade Federal de Pernambuco, Brasi Rose Melo Rocha I Escola Superior de Propaganda e Marketing, Brasil Adriana Braga I Pontifícia Universidade Católica do Rio de Janeiro, Brasil CONSULTORES AD HOC

Virginia Pradelina da Silveira Fonseca I Universidade Federal do Rio Grande do Norte, Brasil Christa Liselote Berger I Universidade do Vale do Rio dos Sinos, Brasil Márcia Benetti I Universidade Federal do Rio Grande do Sul, Brasil Tattiana Gonçalves Teixeira I Universidade Federal de Santa Catarina, Brasil

Gislene da Silva I Universidade Federal de Santa Catarina, Brasil José Afonso Junior I Universidade Federal de Pernambuco, Brasil EDIÇÃO DE TEXTO E RESUMOS I Everton Cardoso

TRADUÇÕES PARA O INGLÊS I Sieni Campos, Lisa Earl Castillo e Sabrina Glendhill EDITORAÇ̃̃ ELETRÔNICA I Roka Estúdio
COMPOS I wWw.compos.org.br

Associação Nacional dos Programas de Pós-Graduação em Comunicação

Presidente

Itania Maria Mota Gomes

Universidade Federal da Bahia, Brasil

itania@ufba.br

Vice-presidente

Julio Pinto

Pontifícia Universidade Católica de Minas Gerais, Brasil juliopinto@pucminas.br

Secretária-Geral

Ana Carolina Escosteguy

Pontifícia Universidade Católica do Rio Grande do Sul, Brasil carolad@pucrs.br 